\title{
Hydrogen Damage in Superaustenitic 904L Stainless Steels
}

\author{
J. Michalska, B. Chmiela, J. Łabanowski, and W. Simka
}

(Submitted September 22, 2013; in revised form March 12, 2014; published online May 20, 2014)

\begin{abstract}
In this work, results on the influence of hydrogen on corrosion resistance and of hydrogen embrittlement of 904L superaustenitic stainless steel were investigated. The cracking behavior was studied by performing a slow strain rate test in synthetic seawater under varying cathodic polarization conditions. The results showed that the steel's plasticity varied with the applied cathodic current density. Significant reductions in ductility were found, indicating its susceptibility to hydrogen-assisted fracture at current density of $20 \mathrm{~mA} /$ $\mathrm{cm}^{2}$. Fractographical examinations showed that an increase in hydrogenation current density causes a stepwise decrease in ductility on the fracture surface. The effect of hydrogen on passivity and on pitting corrosion resistance was qualified with the polarization curves registered in synthetic seawater. The conclusion is that hydrogen may affect the passive film stability and thus may decrease the corrosion resistance of the studied steel. The presence of hydrogen increases corrosion current density and decreases the potential of the film breakdown. It was also found that the degree of the susceptibility to hydrogen degradation was dependent on the hydrogen charging conditions.
\end{abstract}

Keywords fractography, hydrogen damage, pitting, slow strain rate test (SSRT), superaustenitic stainless steel

\section{Introduction}

The phenomenon of hydrogen damage has been prominent in discussions of many technological and corrosion processes for many years. Although hydrogen embrittlement (HE) has been recognized and intensively investigated for more than one century and a half, the mechanisms are still not clearly understood. General trends and concepts have been formed and are used as guidelines in predicting the behavior of engineering alloys exposed to hydrogen.

The interaction between hydrogen and metastable austenitic stainless steels is a unique case (Ref 1). Hydrogen can facilitate the phase transformation of austenite to martensite (Ref 2-4), and the martensite phase is suspected to be more susceptible to hydrogen embrittlement. Competing factors add to the complexity of the phenomenon, but they must be examined

This article is an invited paper selected from presentations at the 9 th International Conference on Diffusion in Solids and Liquids: DSL2013, held June 24-28, 2013, in Madrid, Spain, and has been expanded from the original presentation.

J. Michalska, B. Chmiela, and W. Simka Silesian University of Technology, 44-100 Gliwice, Poland and Institute of Materials Science, Krasińskiego 8, 40-098 Katowice, Poland; and J. Labanowski, Gdansk University of Technology, 90-233 Gdansk, Poland. Contact e-mail: joanna.k.michalska@polsl.pl.

in order to learn how to limit the hydrogen's detrimental effect. It is of great importance for the hydrogen economy to reveal details of the hydrogen effect on austenitic stainless steel.

There are many factors which influence the sensitivity of stainless steels to hydrogen interaction: environment, stress, microstructure, and the manufacturing processes. Chemical composition may also play an important role in the selection of materials regarding their resistance to hydrogen. The degree of austenite stability against hydrogen embrittlement can be evaluated by an equation of $\mathrm{Ni}$ equivalent based on the equation by Hirayama (Ref 5$)$ : $\mathrm{Ni}_{\mathrm{eq}}=\mathrm{Ni}+0.65 \mathrm{Cr}+0.98 \mathrm{Mo}+$ $1.05 \mathrm{Mn}+0.35 \mathrm{Si}+12.6(\mathrm{C}+\mathrm{N})$. Common grades of austenitic steels may seriously suffer from hydrogen; thus, the improvement of the resistance to hydrogen damage has been expected by appropriate alloying and can be correlated with $\mathrm{Ni}$ equivalent. The main elements, as $\mathrm{Ni}$ and $\mathrm{Mo}$, improve the resistance to hydrogen damage by stabilizing the austenite phase with respect to the martensitic transformation and by increasing the stacking fault energy (SFE) to promote cross slip. The addition of $\mathrm{N}$ also stabilizes the austenite phase and improves the resistance to hydrogen damage. Although $\mathrm{N}$ does not change the SFE, $\mathrm{N}$ promotes planar slip by inducing a short-range order in the matrix (Ref 6). Thus, highly alloyed austenitic steels may become a new alternative material, assuring high level of safety in hydrogen-related technologies.

\section{Experimental Procedure}

\subsection{Material}

The material for the research was a plate, $25 \mathrm{~mm}$ in thickness made of superaustenitic grade $1.4539 \mathrm{X} 1 \mathrm{NiCrMoCu}$ 25.20.5. The nominal chemical composition of the investigated steel is presented in Table 1 . 
Table 1 Chemical composition of the $904 \mathrm{~L}$ stainless steel

\begin{tabular}{lcccccccccrr}
\hline $\mathbf{C}$ & $\mathbf{C r}$ & $\mathbf{N i}$ & $\mathbf{M o}$ & $\mathbf{C u}$ & $\mathbf{M n}$ & $\mathbf{S i}$ & $\mathbf{P}$ & $\mathbf{S}$ & $\mathbf{N}$ & $\mathbf{F e}$ \\
\hline 0.021 & 21.36 & 25.62 & 4.56 & 1.72 & 1.7 & 0.70 & 003 & 0.003 & 0.15 & Balance \\
\hline
\end{tabular}

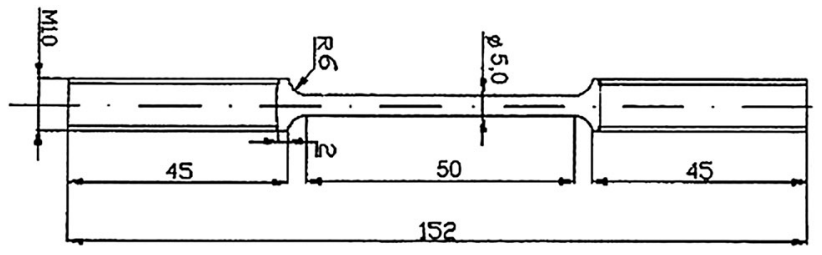

Fig. 1 Specimen geometry for SSR tests

\subsection{Slow Strain Rate Tests}

Slow strain rate testing (SSRT) technique according to EN ISO 7539-7 was employed with an aim of evaluating the susceptibility to hydrogen embrittlement of the investigated steel. Cylindrical specimens (Fig. 1) of $(10.0 \pm 0.2) \mathrm{mm}$ outer diameter, with a gage section of $(5.0 \pm 0.2) \mathrm{mm}$ and $(50.0 \pm 0.2) \mathrm{mm}$ length, were used for the SSRTs.

SSRTs were conducted under various cathodic current density conditions (from ( 1 to 20$) \mathrm{mA} / \mathrm{cm}^{2}$ ), at a constant strain rate of $1 \times 10^{-6} 1 / \mathrm{s}$. The solution for the SSRT was synthetic seawater type A according to the PN-66/C-06502 standard.

After a final rinse with acetone, the tensile specimen was immersed in the test environment in a specially designed chamber mounted in tensile testing machine grips. SSRT tests were continued until the specimens failed. Tests in each of the cathodic current density condition were duplicated. The ultimate tensile strength (UTS) and the uniform elongation (UEL) were recorded during each test. The reduction of the fractured area (RA) and the energy consumed for the failure of the specimen (E) were calculated after each test.

The RAs of the tensile specimens in the SSRT in air and in the solution during charging are named as $\mathrm{RA}$ and $\mathrm{RA}_{\mathrm{H}}$, respectively. The relative plasticity loss during dynamical charging is defined as $\left.\mathrm{HEI}=\left[\left(\mathrm{RA}-\mathrm{RA}_{\mathrm{H}}\right) / \mathrm{RA}\right)\right] \cdot 100$, which is the hydrogen embrittlement index.

Fractographic examinations of the specimens after completion of the SSRTs were carried out using Hitachi S-3400N scanning electron microscope (SEM) in order to characterize the mode of the rupture.

\subsection{Hydrogen Charging and Electrochemical Measurements}

Samples for electrochemical studies were wet ground to a 1200-grit finish on SiC emery papers, followed by 3-step polishing up to a $1-\mu \mathrm{m}$ diamond paste. The polished samples were ultrasonically degreased in alcohol and cleaned with distilled water for hydrogen charging purpose.

Hydrogen was introduced into the samples by the cathodic current method under a galvanostatic condition at room temperature. The charging solution was $0.1 \mathrm{~mol} / \mathrm{dm}^{3}$ $\mathrm{NaOH}+1 \mathrm{mg} / \mathrm{dm}^{3} \mathrm{As}_{2} \mathrm{O}_{3}$. The alkaline solution was used to prevent corrosion damage and to avoid contamination of the sample surface during hydrogen charging. During the cathodic polarization, elemental arsenic coming from $\mathrm{As}_{2} \mathrm{O}_{3}$ is reduced to $\mathrm{AsH}_{3}$, which is the most effective promoter of hydrogen entry into steel (Ref 7). The samples were charged at varying current densities (1-20) $\mathrm{mA} / \mathrm{cm}^{2}$ for 1 week.

Electrochemical investigations were carried out on hydrogen-charged specimens for evaluating their passivity behavior and their corrosion resistance. Polarization curves were recorded in the synthetic seawater type A at ambient temperature. The hydrogen-charged specimens, prepared as described earlier, were immediately transferred from the charging cell to the electrolytic cell for polarization studies. Just before the measurements, samples were quickly rinsed with distilled water and dried by an air flow. The investigations were conducted using a measuring system composed of a computer-controlled Solartron 1287 electrochemical interface and a traditional threeelectrode flat-type cell wherein saturated calomel electrode (SCE) acted as a reference electrode and a platinum wire acted as a counter electrode. The obtained results were elaborated by means of Corrview (Scribner Inc.) software.

A cyclic potentiodynamic polarization technique was used for examining the pitting susceptibility. Just after the immersion of the specimen in an electrolytic cell, open circuit potential (OPC) measurements were first performed for $20 \mathrm{~min}$. Next, the electrode potential was anodically scanned at a rate of $0.167 \mathrm{mV} / \mathrm{s}$ starting from $-300 \mathrm{mV}$ versus open circuit potential (OCP) up to the breakdown potential and then was reversed to study the repassivation tendency. The electrochemical parameters were determined from polarization curves: the breakdown potential $E \mathrm{~b}$ and the repassivation potential Erep. $E$ b was termed as the potential at which a monotonic increase in the anodic current exceeding $25 \mu \mathrm{A} / \mathrm{cm}^{2}$ occurred. Corrosion current density $i_{\text {corr }}$ and corrosion potential $E_{\text {corr }}$ were calculated from polarization curves by Stern-Geary method $( \pm 50 \mathrm{mV}$ versus OCP). Corroded surfaces were examined using a Hitachi S-3400N scanning electron microscope for the evaluation of corrosion attack morphology.

\section{Results}

\subsection{Susceptibility to Hydrogen Embrittlement}

The results of the SSRTs illustrating the effect of hydrogen charging conditions on the mechanical properties of 904L stainless steel are shown in Fig. 2 and Table 2. The stress-strain relationship of 904L stainless steel seemed not to be influenced by hydrogen to the point of causing a significant modification of the yielding point. It was proved that hydrogen charging conditions did not influence the UTS values, despite minor fluctuations. Even after hydrogenation at $10 \mathrm{~mA} / \mathrm{cm}^{2}$, the value of the ultimate tensile strength (UTS) was $567 \mathrm{MPa}$, very close to those obtained from the unhydrogenated condition. On the contrary, a detrimental effect of hydrogen was distinctly observed in case of the reduction in the cross-sectional area (RA) values. As shown in previous results (Ref 8), the RA proved to be the most sensitive measure of embrittlement as caused by the uptake of hydrogen by the steel. The HE phenomenon can be quantitatively described by the hydrogen 
embrittlement index (HEI), which is the reduction of area measured for hydrogenated sample relative to that of the unhydrogenated one. There is no HE when HEI equals $100 \%$, and the HE increases with the increase of the HEI.

The highest loss of plasticity was observed for the sample hydrogenated at $20 \mathrm{~mA} / \mathrm{cm}^{2}$, where the RA decreased to $67.2 \%$ and HEI assess $18 \%$. However, the 904L stainless steel still possesses high level of the resistance to $\mathrm{HE}$ in comparison to duplex stainless steel (DSS) grades (Ref 8, 9).

The results of the mechanical test were in good agreement with the results of the fractographic observation. SEM fractographs of the fracture specimen of 904L stainless steel after the SSRT in synthetic seawater are shown in Fig. 3. As seen in Fig. 3(a), a typical cup and cone failure signifies the ductile failure experienced by the unhydrogenated sample, where a large number of dimples can be observed (Fig. 3b). The fracture morphology of the hydrogen-charged specimens (Fig. 3c-h) appeared to be similar to that of the uncharged specimens and all had the appearance of typical transgranular ductile failures. However, their fracture characteristics are different. The surfaces of hydrogen-charged specimens possess different fracture zones near the edge (Zone A) with mixed fracture, with a lot of small quasi-cleavage brittle areas surrounded by ductile dimples; Zone B was ductile fracture. The extent of zone A was the largest for the sample tested at $20 \mathrm{~mA} / \mathrm{cm}^{2}$.

\subsection{The Effect of Hydrogen on Electrochemical Behavior}

The results of the electrochemical measurements in synthetic seawater are listed in Table 3. Figure 4 shows complete polarization curves of the investigated samples. The analysis of the obtained results revealed that corrosion parameters of $904 \mathrm{~L}$

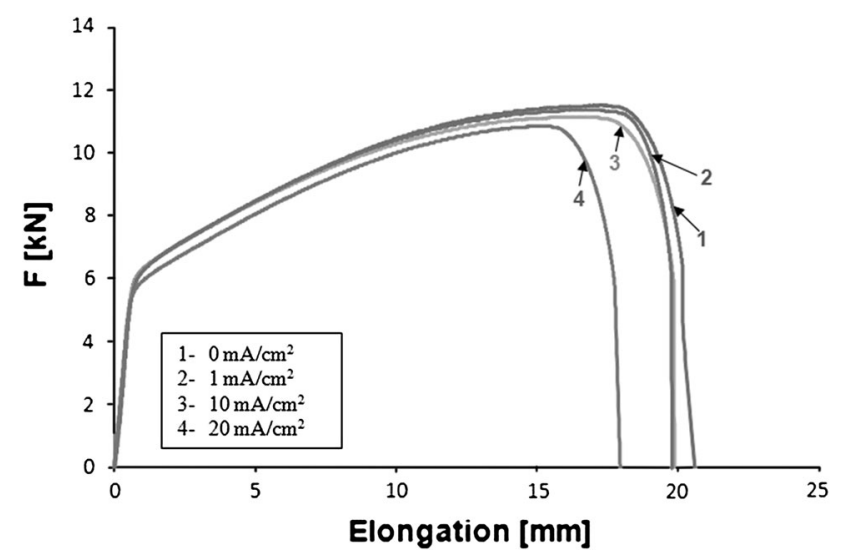

Fig. 2 SSRT stress-elongation curves for 904L stainless steel in synthetic seawater at various applied hydrogenation currents stainless steel are influenced by the presence of hydrogen. However, the effect of hydrogen strongly depends on the cathodic charging conditions. $E_{\text {cor }}$ values of hydrogen-charged samples were more active in comparison to $E_{\text {cor }}$ for the uncharged one. They were found to be more cathodic with the increase of the hydrogen charging current density. The increased corrosion current density $i_{\text {corr }}$ was only observed for the sample charged at $20 \mathrm{~mA} / \mathrm{cm}^{2}$. $i_{\text {corr }}$ values of the samples charged at lower cathodic current ( 1 and $\left.10 \mathrm{~mA} / \mathrm{cm}^{2}\right)$ remain untouched by hydrogen.

Similar observations could be performed for evaluating the passivation and the pitting parameters. The curve for the asreceived steel is typical for strongly passivated material: the anodic current density maintains a value of $\approx 1 \mu \mathrm{A} / \mathrm{cm}^{2}$ until a potential of $\sim 1 \mathrm{~V}$, then an abrupt increase of the current density is observed and $E_{\mathrm{b}}$ values are highly anodic. The presence of hydrogen has changed the course of polarization curves. $E_{\mathrm{b}}$ values were decreased and the size of the corresponding hysteresis loops was higher in comparison to the as-received steel, though this effect was strongly related to the cathodic charging conditions. For higher cathodic charging current, lower $E_{\mathrm{b}}$ and $E_{\text {rep }}$ values were observed. For the as-received material and for the samples that were hydrogen charged up to $10 \mathrm{~mA} / \mathrm{cm}^{2}, E_{\text {rep }}$ values were very close to $E_{\mathrm{b}}$ with a small size of hysteresis loop. The situation has changed for the sample hydrogen charged at $20 \mathrm{~mA} / \mathrm{cm}^{2}$, when a distinct decrease of both pitting parameters was found. These results were in good agreement with microscopic observations of the steel surface after polarization studies. It was proved that for hydrogencharged samples $E_{\mathrm{b}}$ values correspond to breakdown potentials - pits were observed on the steel surface after polarization tests. The amount of pits has been found to depend on the cathodic charging conditions. Small-sized pits were found on the surface for the samples charged with lower cathodic current densities (1 and $10 \mathrm{~mA} / \mathrm{cm}^{2}$ ) (Fig. 5), while severe pitting was observed for the sample charged at $20 \mathrm{~mA} / \mathrm{cm}^{2}$ (Fig. 6).

The presence of hydrogen affected the passivation behavior of the investigated steel. An increase of the passive current density was observed after hydrogenation of steel. This behavior can be attributed to the fact that hydrogen entering a passive film could affect the structure and composition of the film in austenitic grades, although the diffusivity of hydrogen in f.c.c. structure is very low $\left(\sim 10^{-12} \mathrm{~cm}^{2} / \mathrm{s}\right)$. Yashiro et al. (Ref 10), using x-ray photoelectron spectroscopy, found that the permeated hydrogen led to suppression of the aging process of the passive film with respect to enrichment of chromium in AISI 304 stainless steel. Cationic fraction of chromium in a hydrogen-charged passive film was lower than that in an uncharged film. Some authors (Ref 10, 11) assigned the decreased resistance of hydrogen-permeated metals to the increase of hydrogen-containing species, i.e., $\mathrm{OH}^{-}$or $\mathrm{H}_{2} \mathrm{O}$ in the passive film.

Table 2 Summary of SSRT results for $904 \mathrm{~L}$ stainless steel

\begin{tabular}{|c|c|c|c|c|c|}
\hline Sample & $E_{\text {corn }} \mathrm{mV}$ & $i_{\text {corro }} \mu \mathrm{A} / \mathrm{cm}^{2}$ & $R_{\mathrm{p}}, \mathrm{k} \Omega / \mathrm{cm}^{2}$ & $E_{\mathrm{b}}, \mathrm{mV}$ & $E_{\text {rep }}, \mathrm{mV}$ \\
\hline Uncharged & 168 & 0.613 & 42.4 & 1306 & 1348 \\
\hline Charged $1 \mathrm{~mA} / \mathrm{cm}^{2}$ & 162 & 0.682 & 47.2 & 1078 & 1064 \\
\hline Charged $10 \mathrm{~mA} / \mathrm{cm}^{2}$ & -22 & 0.633 & 43.8 & 1062 & 883 \\
\hline Charged $20 \mathrm{~mA} / \mathrm{cm}^{2}$ & -41 & 1.585 & 16.4 & 537 & 160 \\
\hline
\end{tabular}



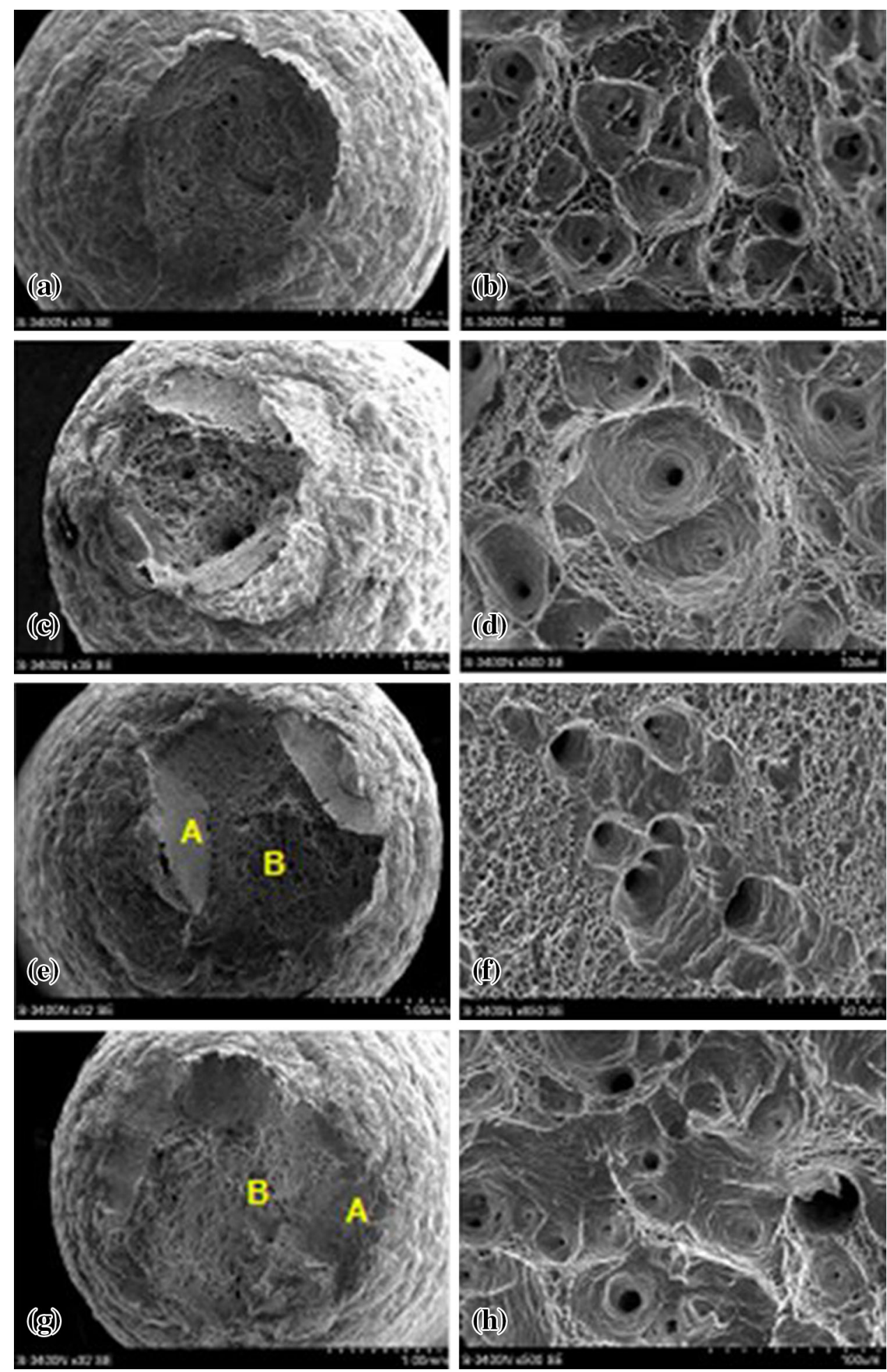

Fig. 3 SEM fractographs of 904L stainless steel fractured in synthetic seawater: $(a, b)$ unhydrogenated sample, hydrogenated samples: $1 \mathrm{~mA} /$ $\mathrm{cm}^{2}(\mathrm{c}, \mathrm{d}), 10 \mathrm{~mA} / \mathrm{cm}^{2}(\mathrm{e}, \mathrm{f})$, and $20 \mathrm{~mA} / \mathrm{cm}^{2}(\mathrm{~g}, \mathrm{~h})$, respectively

The present work showed that hydrogen may seriously disturb and hinder passivation on 904L stainless steel, and the protective layer is then weaker and more defected. Changes in the passive range resulted in the shift of $E_{\mathrm{b}}$ to less noble values, which unequivocally indicates that hydrogen may promote pitting on 904L stainless steel. Significant decrease of the resistance was observed for the highest current density condition $\left(20 \mathrm{~mA} / \mathrm{cm}^{2}\right)$. Up to the charging current of $10 \mathrm{~mA} / \mathrm{cm}^{2}$, the width of passive range exceeds $1 \mathrm{~V}$ and breakdown of passive layer $\left(E_{\mathrm{b}}\right)$ occurred above $1.05 \mathrm{~V}$ versus ECS, still assuring high corrosion resistance. Thus, it was proved that highly alloyed 904L stainless steel possesses higher 
Table 3 The results of polarization measurements

\begin{tabular}{|c|c|c|c|c|c|}
\hline Sample & $E_{\text {corn }}, \mathrm{mV}$ & $i_{\text {corr }} \mu \mathrm{A} / \mathrm{cm}^{2}$ & $R_{\mathrm{p}}, \mathrm{k} \Omega / \mathrm{cm}^{2}$ & $E_{\mathbf{b}}, \mathbf{m V}$ & $E_{\text {rep }}, \mathbf{m V}$ \\
\hline Uncharged & 168 & 0.613 & 42.4 & 1306 & 1348 \\
\hline Charged $1 \mathrm{~mA} / \mathrm{cm}^{2}$ & 162 & 0.682 & 47.2 & 1078 & 1064 \\
\hline Charged $10 \mathrm{~mA} / \mathrm{cm}^{2}$ & -22 & 0.633 & 43.8 & 1062 & 883 \\
\hline Charged $20 \mathrm{~mA} / \mathrm{cm}^{2}$ & -41 & 1.585 & 16.4 & 537 & 160 \\
\hline
\end{tabular}

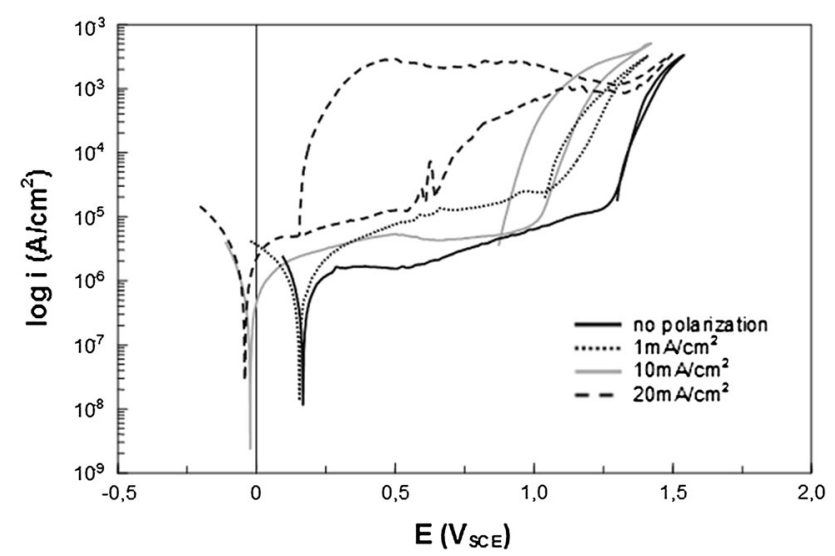

Fig. 4 Polarization curves of 904L stainless steel in synthetic seawater

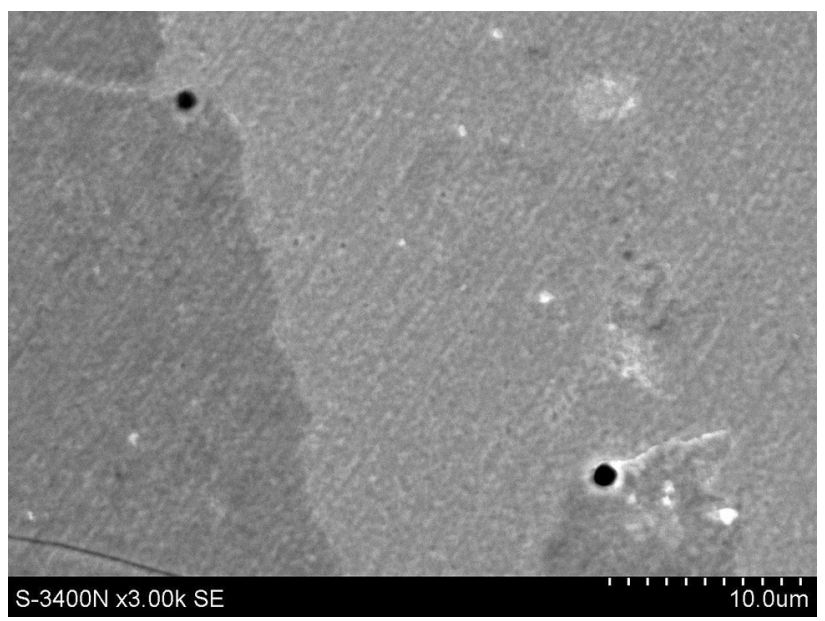

Fig. 5 Surface conditions of the hydrogen-charged steel $\left(1 \mathrm{~mA} / \mathrm{cm}^{2}\right)$

corrosion resistance than the commercial austenitic stainless steel grades. This fact may be attributed to the high $\mathrm{N}$ content in 904L steel. Ningshen et al. (Ref 12) evaluated the hydrogen diffusion, its solubility, and trapping behavior in nitrogencontaining austenitic alloys. They found the lowest hydrogen diffusion and the highest activation energy for diffusion for the alloy with the highest $\mathrm{N}$ content. Increased hydrogen solubility was also observed.

Finally, the possibility that hydrogen decreased the corrosion resistance of 904L stainless steel is much higher than that of the degradation of mechanical properties and hydrogen embrittlement in the investigated steel. Thus, the stability of the passive film is the most important factor in hydrogen damage phenomenon in 904L stainless steel.

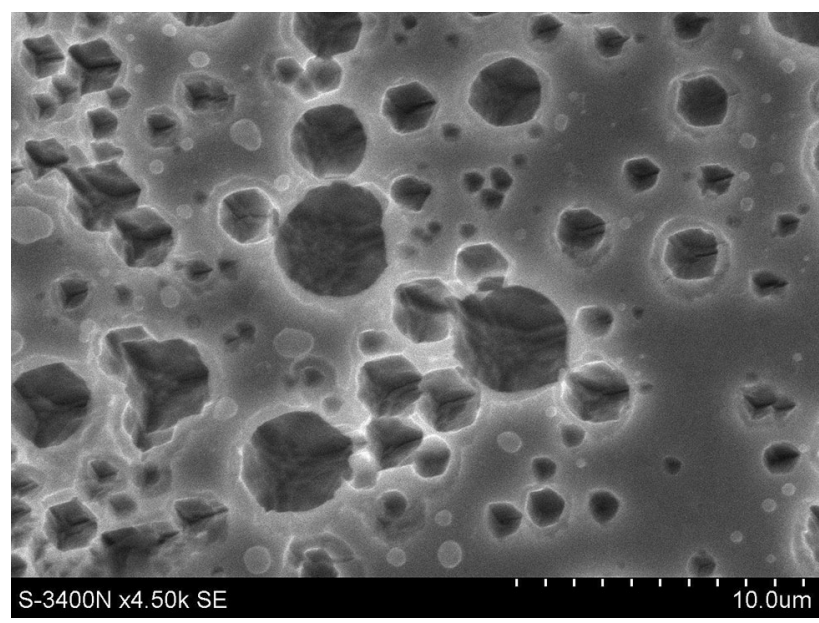

Fig. 6 Severe pitting on the surface of the hydrogen-charged steel $\left(20 \mathrm{~mA} / \mathrm{cm}^{2}\right)$

\section{Conclusions}

The 904L stainless steel possesses a high level of resistance to hydrogen-induced cracking in synthetic seawater. The susceptibility to hydrogen cracking was strongly dependent on the cathodic current density. The higher the cathodic current density and the lower the ductility, the higher is the susceptibility to hydrogen. A detrimental effect of hydrogen was distinctly observed in the case of RA only. Significant loss of resistance to hydrogen embrittlement was observed for the sample hydrogenated at $20 \mathrm{~mA} / \mathrm{cm}^{2}$.

Hydrogen changed the mechanism of microcracking in steel. The ductile failure as revealed by the significant extent of the necking and dimples was obtained in the as-received test. However, after hydrogen charging, fractures became less ductile as well as an increasing number of micro-quasi-cleavage areas were observed, which was highlighted with an increase in the cathodic current density applied during SSRT.

Cathodically evolved hydrogen affects the corrosion resistance of the 904L stainless steel. The presence of hydrogen shifted $E_{\text {corr }}$ to the more active direction and caused a slight increase of the $i_{\text {corr }}$ values.

The presence of hydrogen may seriously disturb and hinder the passivation processes on 904L stainless steel resulting in a decreased resistance to corrosion. This effect was particularly emphasized in the repassivation tendency. Significant loss in corrosion resistance was observed for the sample hydrogenated at $20 \mathrm{~mA} / \mathrm{cm}^{2}$.

\section{Acknowledgment}

The research work was supported by the Silesian University of Technology as a research Project No. BKM-326/RM3/2012. 


\section{Open Access}

This article is distributed under the terms of the Creative Commons Attribution License which permits any use, distribution, and reproduction in any medium, provided the original author(s) and the source are credited.

\section{References}

1. N. Narita and H. Birnbaum, On the Role of Phase Transitions in the Hydrogen Embrittlement of Stainless Steels, Scripta Metall., 1980, 14, p 1355-1358

2. C. Pan, Y.J. Su, W.Y. Chu, Z.B. Li, D.T. Liang, and L.J. Qiao, Hydrogen Embrittlement of Weld Metal of Austenitic Stainless Steels, Corros. Sci., 2002, 44, p 1983-1993

3. Y. Murakami, T. Kanezaki, Y. Mine, and S. Matsuoka, Hydrogen Embrittlement Mechanism in Fatigue of Austenitic Stainless Steels, Metall. Mater. Trans., 2008, 39A, p 1327-1339

4. D. Hardie, J. Xu, E.A. Charles, and Y. Wei, Hydrogen Embrittlement of Stainless Steel Overlay Materials for Hydrogenators, Corros. Sci. 2004, 46, p 3089-3100
5. T. Hirayama and M. Ogirima, Effect of Chemical Composition on Martensite Transformation in Fe-Cr-Ni Stainless Steels, J. Jpn. Inst. Metals, 1970, 361, p 507

6. L. Zhang, M. Wen, M. Imade, S. Fukuyama, and K. Yokogawa, Hydrogen Embrittlement of Austenitic Stainless Steels at Low Temperatures, Environ. Assist. Fract., 2006, 2006, p 1003-1004

7. T. Zakroczymski, Electrochemical Aspects of Hydrogen Entry into Iron and Steel from Aqueous Solutions, Corrosion of Metals and HydrogenRelated Phenomena: Selected Topics, J. Flis, Ed., Elsevier, Amsterdam, 1991,

8. J. Michalska, "The Assessment of Hydrogen Embrittlement Resistance of Duplex Stainless Steel", $\mathrm{PhD}$ thesis, Silesian University of Technology, Katowice, Poland, 2006

9. J. Michalska, J. Labanowski, and J. Ćwiek, Corrosion Induced by Cathodic Hydrogen in 2205 Duplex Stainless Steels, IOP Conf. Ser. Mater. Sci. Eng., 2012, 35, p 012013

10. H. Yashiro, P. Bound, N. Kumagai, and K. Tanno, The Effect of Permeated Hydrogen on the Pitting of Type 304 Stainless Steel, Corros. Sci, 1998, 40, p 781-791

11. S.-I. Pyun and R.A. Oriani, The Permeation of Hydrogen Through the Passivating Films on Iron and Nickel, Corros. Sci., 1989, 29, p 485-496

12. S. Ningshen, U. Kamachi Mudali, G. Amarendra, P. Gopalan, R.K. Dayal, and H.S. Khatak, Hydrogen Effects on the Passive Film Formation and Pitting Susceptibility of Nitrogen Containing Type 316L Stainless Steels, Corros. Sci., 2006, 48, p 1106-1121 